\title{
Author Correction: Chimpanzee ethnography reveals unexpected cultural diversity
}

Christophe Boesch (D), Ammie K. Kalan (1D, Roger Mundry, Mimi Arandjelovic (1D, Simone Pika (D), Paula Dieguez (1), Emmanuel Ayuk Ayimisin, Amanda Barciela @ , Charlotte Coupland, Villard Ebot Egbe, Manasseh Eno-Nku, J. Michael Fay, David Fine, R. Adriana Hernandez-Aguilar (D), Veerle Hermans, Parag Kadam (D), Mohamed Kambi,

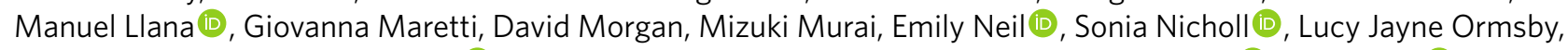

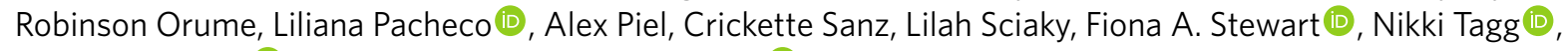
Erin G. Wessling (1), Jacob Willie and Hjalmar S. Kühl(D)

Correction to: Nature Human Behaviour https://doi.org/10.1038/s41562-020-0890-1, published online 25 May 2020.

In the version of this article initially published, affiliations of authors Nikki Tagg and Jacob Willie were listed incorrectly. Dr. Tagg is affiliated with the Centre for Research and Conservation, Royal Zoological Society of Antwerp, Antwerp, Belgium; and with The Born Free Foundation, Horsham, UK. Dr. Willie is affiliated with the Centre for Research and Conservation, Royal Zoological Society of Antwerp, Antwerp, Belgium; and with the Terrestrial Ecology Unit, Ghent University, Ghent, Belgium. The errors have been corrected in the HTML and PDF versions of the article.

Published online: 23 June 2020

https://doi.org/10.1038/s41562-020-0904-Z

(c) The Author(s), under exclusive licence to Springer Nature Limited 2020 